DOI: $10.4274 /$ jarem.galenos.2021.82473

J Acad Res Med 2021;11(3):241-8

\title{
The PR Interval Predicted Major Adverse Cardiovascular Events in Patients with Acute Coronary Syndrome Who Underwent Percutaneous Coronary Intervention: 3 Years Follow-up Results
}

\author{
(1) Ahmet Seyda Yılmaz1, (1) Göksel Çinier2, (1) Fatih Kahraman33, (1) Mustafa Çetin1, (1) Ömer Faruk Çırakoğlu4 \\ ${ }^{1}$ Recep Tayyip Erdoğan University Faculty of Medicine, Department of Cardiology, Rize, Turkey \\ 2University of Health Sciences Turkey, Dr. Siyami Ersek Thoracic and Cardiovascular Surgery Training and Research Hospital, Clinic of \\ Cardiology, İstanbul, Turkey \\ ${ }^{3}$ Kütahya Health Science University Evliya Çelebi Training and Research Hospital, Department of Cardiology, Kütahya, Turkey \\ ${ }^{4}$ Trabzon Ahi Evren Thoracic and Cardiovascular Surgery Training and Research Hospital, Clinic of Cardiology, Trabzon, Turkey
}

Cite this article as: Yılmaz AS, Çinier G, Kahraman F, Çetin M, Çırakoğlu ÖF. The PR Interval Predicted Major Adverse Cardiovascular Events in Patients with Acute Coronary Syndrome Who Underwent Percutaneous Coronary Intervention: 3 Years Follow-up Results. J Acad Res Med 2021;11(3):241-8

\begin{abstract}
Objective: It is crucial to identify the high-risk group in acute coronary syndrome (ACS) patients who underwent percutaneous coronary intervention (PCI). To date, various stratification tools have been developed to predict adverse events. However, the PR interval is a readily available parameter in routine clinical practice. This study aimed to investigate the role of the PR interval in predicting major adverse cardiovascular events (MACE) in patients with ACS who were performed PCI.

Methods: Patients diagnosed with ACS and who underwent PCI between January 2015 and July 2018 were included in the study. Patients were followed up for an average of 3.2 years. Electrocardiogram was obtained from all patients on admission to the hospital. The PR interval was measured by the semi-automatic application tool. The primary outcome was all-cause mortality, new-onset decompensated heart failure, cerebrovascular event, and recurrent revascularization.

Results: The mean age of total 177 ACS patients was $58.7 \pm 10.3$ years and $150(84.7 \%)$ of them were male. MACE developed in 38 patients (21.4\%) who were older $(p<0.001)$ with a male preponderance $(p=0.032)$. The PR interval was shorter in the MACE $(+)$ group than the MACE $(-)$ group (154.2 \pm 21.2 vs $164.1 \pm 18.1 \mathrm{~ms}, \mathrm{p}=0.004)$. Backward multivariable Cox regression analysis revealed that male gender [hazard ratio $(\mathrm{HR})=3.667,95 \%$ confidence interval (Cl): 1.501-8.961, $\mathrm{p}=0.004]$, PR interval [HR=0.981, 95\% Cl:0.961-0.996, $\mathrm{p}=0.019]$, and left ventricular ejection fraction [HR=0.906, 95\% $\mathrm{Cl}: 0.873-0.941$, $\mathrm{p}<0.001]$ were independent predictors of MACE during long-term follow-up.

Conclusion: The PR interval and male gender were independent predictors of long-term MACE in patients with ACS without atrioventricular conduction defect.

Keywords: Acute coronary syndrome, electrocardiography, PR interval, percutaneous coronary intervention, sympathetic activity, major adverse cardiovascular event
\end{abstract}

ORCID IDs of the authors: A.S.Y. 0000-0003-3864-4023; G.Ç. 0000-0001-5064-1816; F.K. 0000-0003-3860-2755; M.Ç. 0000-0001-6342-436X; Ö.F.Ç. 0000-0002-1815-437X. 


\section{INTRODUCTION}

The prognosis of patients with the acute coronary syndrome (ACS) improved considerably with recent developments in medical and interventional treatment options. However, ACS is still one of the leading causes of morbidity and mortality worldwide (1). Thus, determining the high-risk patient population is essential to prevent future adverse events and regulate the aggressivity of treatment modalities (2).

The surface electrocardiogram (ECG) is an easily obtainable, costeffective, and routinely used diagnostic tool that has a vital role in diagnosing and treating patients with ACS (3). The significant prognostic roles of depolarization and repolarization parameters such as QRS duration, OT interval, T-wave peak to T-wave end interval (TPE) interval were shown in previous studies. In addition, conduction disorders including right bundle branch block, left bundle branch block, atrioventricular (AV) block, and fascicular blocks were also demonstrated to be predictors of adverse events in patients with ACS (4-6). Moreover, elevated heart rate was an independent predictor of long-term major adverse cardiovascular events (MACE) in patients with ACS. This result was linked to increased sympathetic activity $(7,8)$.

The PR interval is the duration of the electrical stimulus that has arisen from the sinus node ( $\mathrm{SN}$ ) and travels to the ventricle. The impulse conduction is slowed by the AV node because of the electrophysiological properties of AV nodal tissue (9). Therefore, increased sympathetic and/or decreased parasympathetic stimulation causes shortening of the PR interval by providing more frequent stimulation from the $\mathrm{SN}$ and reducing the delay in the AV node (10). Hence, we aimed to investigate the predictive role of PR interval on MACE development in patients with ACS without AV conduction defect.

\section{METHODS}

\section{Study Population}

This is a prospective and observational cohort study. A total of 177 consecutive patients with a diagnosis of ACS between January and July 2017 were enrolled. Patients were diagnosed with ACS in accordance with the currently recommended ESC/AHA guidelines $(11,12)$. The study was carried out following the principles stated in the Declaration of Helsinki. The Local Ethics Committee approved the study protocol (decision no: E-64247179-799, date: 26.05.2021).

The same cardiologist at admission recorded sociodemographic data and medical history. The systolic and diastolic pressure, previous history of coronary artery disease (CAD), arterial hypertension $(\mathrm{AH})$, diabetes mellitus (DM), hyperlipidemia, smoking status, and family history of premature CAD were evaluated. The patient's use of antihypertensive drugs or systolic blood pressure greater than $140 \mathrm{mmHg}$ or diastolic blood pressure greater than $90 \mathrm{mmHg}$ in two or more measurements were defined as $\mathrm{AH}$. The presence of DM was diagnosed according to at least one of the following criteria: i) history of DM and taking any antidiabetic medication; ii) randomly measured blood glucose value of $200 \mathrm{mg} / \mathrm{dL}$ or higher; iii) $\mathrm{HbA} 1 \mathrm{c}$ values are 6.5 percent or higher. Regular smokers in the last six months were considered as a smoker. The following formula calculated body mass index (BMI): $\mathrm{BMI}=$ weight $(\mathrm{kg}) /$ height $(\text { meters })^{2}$. All data were stored in the database of our institution.

\section{2-Lead Standard Electrocardiogram Records}

Standard 12-lead ECG (Schiller, Cardiovit AT-10 plus) (filter 150 $\mathrm{Hz}, 25 \mathrm{~mm} / \mathrm{s}, 10 \mathrm{~mm} / \mathrm{mV}$ ) was recorded by experienced nurses at admission in all patients. ECG images were magnified eight times using a semi-automatic application tool. Standard intervals (HR, PR, QRS, and QT intervals) and amplitudes ( $R, S$, and $T$ waves and $J$ and ST segments) on the ECG were analyzed by the experienced cardiologist. In addition, measurements of the PR interval were carried in lead II. The PR interval was assessed as the milliseconds from the initial-up point of the $P$ wave to the initial-up point of the $R$ wave or the initial-down point of the $q$ wave. The onset of the $P$ wave was determined as the deviation point up or down from the isoelectric line. The $\mathrm{R}$ wave was determined as the first upward deviation point from the isoelectric line, whereas the $q$ wave was the first downward deviation point. The PR interval was calculated as the average duration of 3 consecutive beats.

\section{Exclusion Criteria}

End-stage liver or kidney disease (7 patients), collagen tissue disease (2 patients), malignancy (3 patients), acute or chronic infectious disease (10 patients), moderate to severe valvular heart disease (7 patients), congenital heart disease (1 patient), and pulmonary embolism (2 patients) were excluded from the study. In addition, patients with atrial fibrillation (AF) (11 patients), AV blocks (10 patients), and percutaneous coronary intervention (PCl)-related complications were not included in the study. Patients taking medications such as beta-blockers and calcium channel blockers before PCl, which may alter the PR interval (10 patients) were also excluded.

In accordance with the principle of the clinical trials, patients who did not sign the informed consent form, refused $\mathrm{PCl}$, and patients whose information could not be accessed (25 patients) from the hospital's medical system records, national death database system, or telephone numbers were excluded from the study.

\section{Coronary Angiography and Percutaneous Coronary Intervention}

Coronary angiography was performed urgently by the transfemoral Judkins technique preferably. However, the trans-radial Judkins technique was used in case of difficulties in accessing the ascendant aortic artery. The left anterior descending and circumflex coronary arteries were viewed from the right and left cranial and caudal angles. The right coronary artery was visualized from at least two different angles. Patients were given the loading dose of acetylsalicylic acid and clopidogrel or ticagrelor according 
to the preference of the invasive cardiologist who performed the procedure. At the beginning of the procedure, 5,000 or 10,000 IU intra-venous heparin was administered according to the patients' weight. After the invasive procedure, all patients were taken to the coronary critical care unit and followed until stabilization was achieved.

\section{Echocardiography}

Detailed two-dimensional echocardiography was performed in all patients before discharge. Echocardiography was conducted in the left lateral decubitus position with Philips Epiq 7 systems (Philips Medical Systems, Andover, MA) using a 2.5-3.5 Mhz transducer. Left ventricular ejection fraction (LVEF) was measured using the modified Simpson's method. Conventional Doppler echocardiography and tissue Doppler imaging data were also obtained from all patients. The physicians who performed echocardiography were blinded to the other clinical conditions of the patients.

\section{Clinical and Laboratory Data Assessment}

At admission, routine biochemistry, hemogram, creatinine kinaseMB fraction (CK-MB), troponin-I, glucose, and C-reactive protein (CRP) were measured. Glucose, creatinine, and lipid parameters were measured with standard methods. Peak CK-MB and peak troponin levels were measured at admission and 4-hour apart. Peak values were included in the analysis. Since laboratory measurements of $50 \mathrm{ng} / \mathrm{mL}$ and above are stated as $>50 \mathrm{ng} / \mathrm{mL}$ in our institution, if the peak value exceeds $50 \mathrm{ng} / \mathrm{mL}$, troponin was included as " 50 " in the statistical analysis.

\section{Clinical Follow-up and The Primary Outcome}

The patients were followed up for an average of 3.2 years. The composite primary endpoint of the study was all-cause mortality, new-onset decompensated heart failure (HF), cerebrovascular event, and recurrent revascularization. Mortality data were obtained by the query of the hospital and national databases or with direct phone calls to relatives of relevant patients. Most of the patients were examined at $1^{\text {st }}, 3^{\text {rd }}, 6^{\text {th }}, 12^{\text {th }}, 24^{\text {th }}$ months, and clinical and laboratory findings were regularly recorded to the hospital database system. For patients who were not admitted to the hospital for regular control, relevant medical histories were obtained through the medical system records of the hospital. Typical HF symptoms, including shortness of breath, swelling of ankles, palpitation, weakness, jugular venous fullness, pulmonary congestion, and peripheral edema, were assessed at the examinations. Patients with the symptoms mentioned above and physical examination findings and those with LVEF under $40 \%$ were accepted as decompensated heart failure (CHF).

\section{Statistical Analysis}

SPSS software package (Version 23.0, SPSS, Inc., Chicago, IL) was used to analyze the data. The normal distribution of the data was assessed by the visual (histograms, probability plots) and analytical methods such as Kolmogorov-Smirnov (if the number of related parameters is more than 50) and Shapiro-Wilk's test (if the number of related parameters is less than 50). Levene's test was used to check the homogeneity of variances. The mean \pm standard deviation was used to represent the continuous variables, median. The interquartile range was used for nonnormally distributed continuous variables, and the percentages were used to present the categorical variables. The chi-square or Fisher's Exact test was used for comparing the categorical groups. The two-tailed Student t-test was used for normally distributed parameters, while the Mann-Whitney $U$ test was performed for the non-normally distributed continuous variables. The effects of the various variables on MACE were determined by univariate regression analysis. In univariate analyses, the variables with unadjusted $p<0.05$ and considered to be related to MACE were identified as confounding factors and included in the multivariable Cox regression analyses to determine the independent predictors of MACE. A p-value (2-tailed) of less than 0.05 was considered to have statistical significance. Kaplan-Meier curve was drawn to show the PR interval in predicting MACE.

\section{RESULTS}

A total of 177 patients were included in this study. The mean age was $58.7 \pm 10.3$ years and 150 patients $(84.7 \%)$ were male. The patients were divided into two groups according to the presence of MACE which occurred in 38 patients (21.4\%). Of those, $7(18 \%)$ died, $19(50 \%)$ had decompensated HF, $6(8 \%)$ had cerebrovascular event, and $9(23 \%)$ had recurrent revascularization. MACE (+) group was older $(63.9 \pm 11.5$ vs $57.28 \pm 9.6, p<0.001)$ and more likely to be male ( $73.7 \%$ vs $12.2 \%, p=0.032)$. While LVEF $(48.7 \pm 10.8$ vs $56.2 \pm 6.5, p<0.001)$ and eGFR ( 81 vs $89.5 \mathrm{~mL} / \mathrm{min} / 1.73 \mathrm{~m}^{2}$, $p=0.020)$ were lower, peak troponin $(28.5 \pm 22.5$ vs $19.2 \pm 20.4 \mathrm{ng} /$ $\mathrm{mL}, \mathrm{p}=0.015$ ) and $\mathrm{CRP}(1.1 \mathrm{vs} 0.6 \mathrm{mg} / \mathrm{dL}, \mathrm{p}=0.005$ ) were higher in MACE (+) group. Type of ACS $(p=0.245)$ and other demographic features were similar between groups (Table 1).

The PR interval was shorter $(154.2 \pm 21.2$ vs $164.1 \pm 18.1 \mathrm{~ms}$, $p=0.004)$, whereas HR was higher in MACE (+) group. However, HR did not reach statistical significance $(76.9 \pm 15.8$ vs $72.1 \pm 14.1$ bpm, $p=0.068)$. Other electrocardiographic findings did not differ between MACE groups (Table 2). In addition, patients were divided into two groups as longer (above mean 164) and shorter (below mean 164) PR intervals. Demographic characteristics of patients were similar between PR interval groups. However, overall MACE, mortality, and repeated revascularization rates were higher in the shorter PR interval group (Table 3).

The parameters that found significant in univariate analysis were included in backward multivariable Cox regression analysis which revealed that age [HR=3.667, 95\% confidence interval $(\mathrm{Cl})$ : 1.501-8.961, $p=0.004]$, PR interval [HR=0.981, 95\% Cl:0.961-0.996, $\mathrm{p}=0.019]$, and LVEF [HR=0.906, 95\% Cl:0.873-0.941, $p<0.001]$ were independent predictors of MACE (Table 4). Kaplan-Meier curves demonstrated that longer PR interval $(<164 \mathrm{~ms})$ increased the risk of MACE during 3.2 years of follow-up (Figure 1). 
Table 1. Comparison of the characteristic features of patients with and without MACE

\section{Variables \\ Demographic characteristics}

Gender (male) n (\%)

Hypertension $n(\%)$

Smoking $n$ (\%)

Hyperlipidemia $n(\%)$

Diabetes mellitus $n(\%)$

Previous CAD n (\%)

Age (year)

Body mass index $\left(\mathrm{kg} / \mathrm{m}^{2}\right)$

Admission SBP (mmHg)

Admission DBP (mmHg)

LVEF (\%)

Mortality $n$ (\%)

Decompensated HF n (\%)

Repeated revascularization $\mathrm{n}(\%)$

Cerebrovascular event $\mathrm{n}(\%)$

Type of AMI

USAP/NSTEMI n (\%)

STEMI n (\%)

IRA

LAD n (\%)

RCA $n(\%)$

$\mathrm{CX} n(\%)$

Stent type $n(\%)$

BMS stent type $\mathrm{n}(\%)$

DES stent type $n(\%)$

BMS+DES stent type $n(\%)$

Final TIMI flow $\mathbf{n}(\%)$

0-1 n (\%)

$2 n(\%)$

$3 n(\%)$

\section{Admission laboratory}

Serum creatinine $(\mathrm{mg} / \mathrm{dL})$

eGFR $\left(\mathrm{mL} / \mathrm{min} / 1.73 \mathrm{~m}^{2}\right)^{\star}$

Peak troponin (ng/mL)

Glucose (mg/dL)

$\mathrm{HgbA1c}$

CRP $(\mathrm{mg} / \mathrm{dL})$ *

Hemoglobin (g/dL)

WBC $10^{3} / \mu \mathrm{L}$

\section{Medication at discharge}

Aspirin $n(\%)$

Clopidogrel n (\%)

Prasugrel $n$ (\%)

Ticagrelor $n(\%)$

ACEI $n$ (\%)

ARB n (\%)

Beta-blocker n (\%)

OAD/insulin $n(\%)$

\section{MACE (-) (n=139)}

$122(87.8)$

62 (44.6)

$17(12.2)$

$47(33.8)$

$51(36.7)$

$12(13.5)$

$57.28 \pm 9.6$

$29.3 \pm 4.6$

$126.8 \pm 19.3$

$76.7 \pm 11.6$

$56.2 \pm 6.5$

$0(0)$

$0(0)$

$0(0)$

$0(0)$

$98(70)$

$41(29)$

$35(41)$

31 (36)

20 (23)

$11(14)$

70 (78)

8 (9)

2 (2)

6 (6)

95 (92)

\begin{tabular}{l}
$0.92 \pm 0.19$ \\
$89.5(75.7-98.2)$ \\
$19.2 \pm 20.4$ \\
$133.3 \pm 53.1$ \\
\hline $5.9(5.7-6.7)$ \\
$0.63(0.32-1.14)$ \\
$14.5 \pm 1.7$ \\
$10.4 \pm 3.5$
\end{tabular}

$116(100)$

59 (50.9)

$12(10.3)$

41 (35.3)

72 (62.1)

22 (19)

87 (75)

51 (36.7)
MACE $(+)(n=38)$

$28(73.7)$
$18(47.4)$
$7(20)$
$10(26.3)$
$14(36.8)$
$6(20)$
$63.9 \pm 11.5$
$30.7 \pm 6.2$
$132 \pm 21.4$
$79.9 \pm 16.8$
$48.7 \pm 10.8$
$7(18)$
$19(50)$
$9(23)$
$6(8)$

23 (60)

15 (39)

17 (48)

11 (31)

7 (20)

4 (11)

25 (71)

6 (17)

3 (10)

1 (3)

$26(86)$

$0.95 \pm 0.21$
$81(71.5-92)$
$28.5 \pm 22.5$
$142.3 \pm 59.5$
$6(5.7-7.3)$
$1.1(0.61-2.63)$
$14.3 \pm 1.8$
$9.9 \pm 2.4$

31 (96.9)

18 (56.3)

2 (6.3)

10 (31.3)

14 (43.8)

$11(34.4)$

25 (78.1)

14 (36.8)
All patients $(n=177)$

$150(84.7)$

0.032

80 (45.2)

0.762

24 (13.2)

0.323

57 (32.2)

0.381

65 (36.7)

0.986

119 (67.2)

0.389

$58.7 \pm 10.3$

$<0.001$

$29.6 \pm 5$

0.159

$127.9 \pm 19.8$

0.155

$77.4 \pm 12.9$

0.175

$54.2 \pm 8.5$

7 (39)

19 (11)

9 (1)

$6(0.5)$

$<0.001$

$<0.001$

$<0.001$

$<0.001$

$<0.001$

121 (69)

56 (31)

0.245

52 (43)

42 (34)

27 (22)

0.425

15 (12)

95 (76)

14 (11)

0.203

5 (4)

7 (5)

121 (90)

0.113

\begin{tabular}{|l|l|}
\hline $0.93 \pm 0.19$ & 0.495 \\
\hline $84.1 \pm 17$ & 0.020 \\
\hline $21.2 \pm 21.1$ & 0.015 \\
\hline $135 \pm 54.5$ & 0.371 \\
\hline $5.9(5.7-6.7)$ & 0.877 \\
\hline $1.08 \pm 1.8$ & 0.003 \\
\hline $14.4 \pm 1.7$ & 0.748 \\
\hline $10.3 \pm 3.3$ & 0.486 \\
\hline
\end{tabular}

147 (99.3)

0.998

77 (50)

0.598

$14(9.5)$

0.483

51 (28.8)

0.666

86 (58.1)

0.063

33 (18.6)

0.064

112 (75.7)

0.715

31 (20.9)
0.986

Continuous variables are given as mean \pm standard deviation. ${ }^{\star}$ Median, interquartile range [range, (25\%-75\%)]. MACE: major adverse cardiovascular events, CAD: coronary artery disease, SBP: systolic blood pressure, DBP: diastolic blood pressure, LVEF: left ventricular ejection fraction, HF: heart failure, AMI: acute myocardial infarction, USAP: unstable angina pectoris, NSTEMI: non-ST-segment elevated myocardial infarction, IRA: infarct-related artery, LAD: left anterior descending, RCA: right coronary artery, CX: circumflex, TIMI: thrombolysis in myocardial infarction, CRP: C-reactive-protein, WBC: white blood cell, OAD: oral antidiabetic drug 


\section{DISCUSSION}

In the present study, we demonstrated that the admission PR interval, without AV conduction defect, was an independent predictor of long-term MACE in patients with ACS. Thus, to the best of our knowledge, this study is the first in the literature to evaluate the relationship between the PR interval and MACE in patients with ACS.

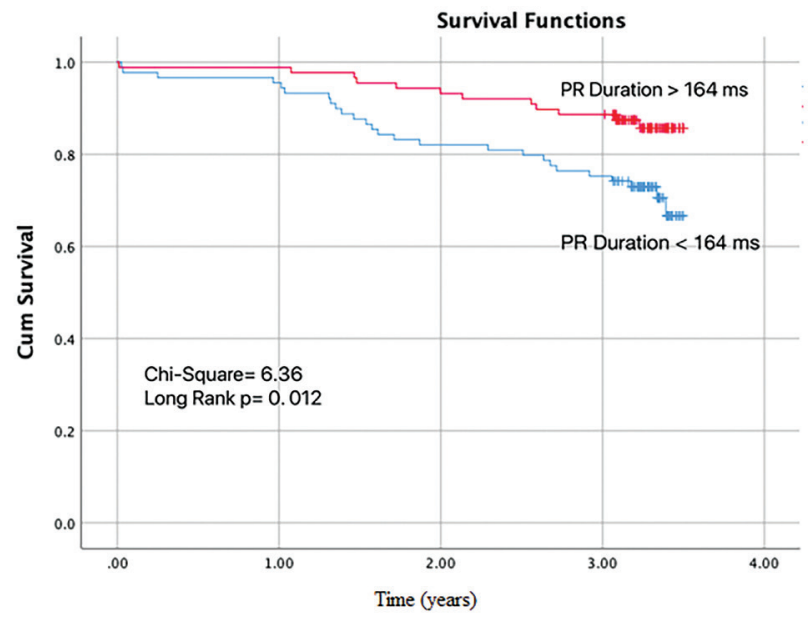

Figure 1. Kaplan-Meier curves demonstrated that PR interval of over 164 ms increased the risk of MACE during 3.2 years of follow-up

MACE: major adverse cardiovascular events
Autonomic nervous system (ANS) activation has an important role in the hemostatic control and the progression of cardiovascular diseases (13). Sympathetic nervous system (SNS) activation increases the HR and left ventricular contraction and accelerates the intracardiac electrophysiological propagation velocity (14). Analysis of adrenergic neural functions can predict adverse events that may develop subsequently. Sinus node activity was increased in the early stage of ACS, and sympathetic activation was associated with adverse outcomes (15). Graham et al. (16) showed that LVEF was lower in the late-stage in patients whose sympathetic activity was higher in patients with acute myocardial infarction (AMI). Xiong et al. (17) demonstrated in their experimental studies that adverse remodeling and LV systolic dysfunction after AMI were of a lesser extent in patients who underwent sympathetic neural ablation. In Takatsubo cardiomyopathy, hyperactivation of the adrenergic activity was blamed for the aneurysm in the apical segment of the left ventricle (18). In addition, increased sympathetic activity and/or decreased vagal activity were shown to induce malignant arrhythmias in various populations. Furthermore, stimulation of arrhythmias by increased sympathetic activity becomes more apparent at higher HR. Especially, acute ischemic episodes of myocardium trigger malignant arrhythmia at higher HR furtherly (19). The mortality rate was shown to reduce considerably employing shifting the autonomic balance in favor of vagal tonus with medical or interventional treatment modalities. Thus, activating parasympathetic activity with beta-blockers and reducing sympathetic tonus with angiotensin-converting enzyme inhibitors are the main focuses of improving survival (20).

\section{Table 2. Electrocardiographic findings of patients}

\section{Variables}

Heart rate (beat/min)

$P$ wave duration (ms)

$P$ wave peak time (ms)

$P$ wave dispersion (ms)

PR interval (ms)

$P$ wave amplitude (mm)

$P$ wave terminal force ( $\mathrm{ms}$ )

QRS duration (ms)

AIAB n (\%)

PAIAB n (\%)

QT dispersion n (\%)

QTc interval (ms)

QT interval (ms)

QT dispersion (ms)

TPE (ms)

TPE/OT rate

QT/OTc rate

TPE/QTc rate

Min: minute, TPE: T-wave end interval

\section{MACE (-)}

$72.1 \pm 14.1$

$110 \pm 15.6$

$55.5 \pm 13.3$

$22.6 \pm 15.3$

$164.1 \pm 18.1$

$0.88 \pm 0.27$

$64.4 \pm 29.9$

$89.7 \pm 14.1$

11 (7.9)

$42(30.2)$

54 (45.4)

$427.2 \pm 34.8$

$395.3 \pm 37.2$

$39.6 \pm 22.9$

$81.9 \pm 16.8$

$0.21 \pm 0.04$

$0.92 \pm 0.09$

$0.2 \pm 0.035$

\section{MACE (+)}

$76.9 \pm 15.8$

$104.9 \pm 19.3$

$52.8 \pm 13.9$

$22.5 \pm 16.7$

$154.2 \pm 21.2$

$0.80 \pm 0.28$

$57.9 \pm 34.6$

$91.1 \pm 14.7$

2 (5.3)

8 (21.2)

10 (32.2)

$432.2 \pm 30$

$387 \pm 42.2$

$33.03 \pm 21.9$

$82.9 \pm 14.9$

$0.21 \pm 0.03$

$0.89 \pm 0.09$

$0.2 \pm 0.034$

\begin{tabular}{|l|l|}
\hline All patients & $p$ \\
\hline $73 \pm 14.6$ & 0.068 \\
\hline $108.9 \pm 16.4$ & 0.094 \\
\hline $54.9 \pm 13.4$ & 0.285 \\
\hline $22.6 \pm 15.9$ & 0.950 \\
\hline $162 \pm 19.1$ & 0.004 \\
\hline $0.8 \pm 0.2$ & 0.134 \\
\hline $63 \pm 31$ & 0.294 \\
\hline $90 \pm 14.2$ & 0.615 \\
\hline $13(7.3)$ & 0.579 \\
\hline $50(28.2)$ & 0.266 \\
\hline $64(36.1)$ & 0.188 \\
\hline $428.2 \pm 33.8$ & 0.143 \\
\hline $393.5 \pm 38.3$ & 0.457 \\
\hline $38.3 \pm 22.8$ & 0.147 \\
\hline $81.8 \pm 16.5$ & 0.758 \\
\hline $0.2 \pm 0.03$ & 0.980 \\
\hline $0.92 \pm 0.09$ & 0.076 \\
\hline $0.2 \pm 0.034$ & 0.990 \\
\hline
\end{tabular}

0.068

0.094

0.285

0.950

0.004

0.134

0.294

0.615

0.579

0.266

0.188

0.143

0.457

0.147

0.758

0.980

0.990 
Table 3. Comparison of the characteristic features of patients according to the PR interval

\begin{tabular}{|c|c|c|c|}
\hline Variables & $\begin{array}{l}\text { Short PR interval } \\
(n=85)\end{array}$ & $\begin{array}{l}\text { Long PR interval } \\
(n=92)\end{array}$ & $p$ \\
\hline \multicolumn{4}{|l|}{ Demographic characteristics } \\
\hline Gender (male) n (\%) & 70 (82.4) & $80(87)$ & 0.260 \\
\hline Hypertension n (\%) & $38(9.4)$ & $16(17.4)$ & 0.862 \\
\hline Smoking n (\%) & $8(12.2)$ & $7(20)$ & 0.121 \\
\hline Hyperlipidemia n (\%) & $23(27.1)$ & $34(37)$ & 0.159 \\
\hline Diabetes mellitus n (\%) & $36(42.4)$ & 29 (31.5) & 0.135 \\
\hline Previous CAD n (\%) & $9(15.8)$ & $9(14.5)$ & 0.846 \\
\hline Age (year) & $59.1 \pm 10.8$ & $58.3 \pm 9.9$ & 0.594 \\
\hline Body mass index $\left(\mathrm{kg} / \mathrm{m}^{2}\right)$ & $29.5 \pm 5.2$ & $29.8 \pm 4.8$ & 0.697 \\
\hline Admission SBP (mmHg) & $127.2 \pm 19.6$ & $128.6 \pm 20$ & 0.636 \\
\hline Admission DBP (mmHg) & $76 \pm 13.8$ & $78 \pm 11.9$ & 0.160 \\
\hline LVEF (\%) & $53.4 \pm 8.8$ & $55.1 \pm 8.1$ & 0.275 \\
\hline MACE n (\%) & $26(30.6)$ & $12(13)$ & 0.006 \\
\hline Mortality n (\%) & $7(8.2)$ & $0(0)$ & 0.005 \\
\hline Decompensated HF n (\%) & $11(12.9)$ & $8(8.7)$ & 0.362 \\
\hline Repeated revascularization $n(\%)$ & $8(9.4)$ & $1(1.1)$ & 0.012 \\
\hline Cerebrovascular event n (\%) & $4(4.7)$ & $2(2.2)$ & 0.352 \\
\hline \multicolumn{4}{|l|}{ Type of AMI } \\
\hline USAP/NSTEMI n (\%) & $58(68.2)$ & $63(68.5)$ & \multirow{2}{*}{0.972} \\
\hline STEMI n (\%) & 27 (31.8) & $29(31.5)$ & \\
\hline \multicolumn{4}{|l|}{ Final TIMI flow n (\%) } \\
\hline $0-1 \mathrm{n}(\%)$ & $4(6.5)$ & $1(1.4)$ & \multirow{3}{*}{0.310} \\
\hline $2 n(\%)$ & $3(4.8)$ & $4(5.6)$ & \\
\hline 3 n (\%) & $55(88.7)$ & $66(93)$ & \\
\hline Creatinine (mg/dL) & $0.91 \pm 0.21$ & $0.94 \pm 0.17$ & 0.383 \\
\hline eGFR $\left(\mathrm{mL} / \mathrm{min} / 1.73 \mathrm{~m}^{2}\right)^{*}$ & $84.1(73-86.5)$ & $81(71.5-92)$ & 0.020 \\
\hline Peak troponin (ng/mL) & $25.6 \pm 20.9$ & $17.1 \pm 20.7$ & 0.009 \\
\hline Glucose (mg/dL) & $133.3 \pm 53.1$ & $142.3 \pm 59.5$ & 0.371 \\
\hline $\mathrm{HgbA1c}$ & $6.1 \pm(5.6-8.1)$ & $5.8(5.7-6.2)$ & 0.122 \\
\hline $\operatorname{CRP}(\mathrm{mg} / \mathrm{dL})^{\star}$ & $0.711(0.38-1.44)$ & $0.713(0.41-1.37)$ & 0.504 \\
\hline Hemoglobin (g/dL) & $14.3 \pm 1.9$ & $14.5 \pm 1.5$ & 0.488 \\
\hline WBC $10^{3} / \mu \mathrm{L}$ & $10.7 \pm 2.9$ & $10.5 \pm 3.8$ & 0.264 \\
\hline
\end{tabular}

Continuous variables are given as mean \pm standard deviation. *Median, interquartile range [range, (25\%-75\%)]. MACE: major adverse cardiovascular events, CAD: coronary artery disease, SBP: systolic blood pressure, DBP: diastolic blood pressure, LVEF: left ventricular ejection fraction, HF: heart failure, AMI: acute myocardial infarction, USAP: unstable angina pectoris, NSTEMI: non-ST-segment elevated myocardial infarction,

TIMI: thrombolysis in myocardial infarction, CRP: C-reactive-protein, WBC: white blood cell

Table 4. Multivariable Cox regression analysis of parameters that predicting MACE

\begin{tabular}{|c|c|c|c|c|c|c|}
\hline \multirow[b]{2}{*}{ Variables } & \multicolumn{3}{|c|}{ Univariate } & \multicolumn{3}{|c|}{ Multivariable } \\
\hline & OR & $95 \% \mathrm{Cl}$ & $p$ & $H R$ & $95 \% \mathrm{Cl}$ & $p$ \\
\hline Age & 1.052 & $1.021-1.084$ & 0.001 & - & - & - \\
\hline PR interval (ms) & 0.978 & 0.963-0.993 & 0.005 & 0.981 & $0.961-0.996$ & 0.019 \\
\hline LVEF (\%) & 0.920 & 0.889-0.952 & $<0.001$ & 0.906 & $0.873-0.941$ & $<0.001$ \\
\hline eGFR (mL/min/1.73 m²) & 0.239 & $0.058-0.993$ & 0.049 & - & - & - \\
\hline
\end{tabular}


ANS activity is evaluated by indirect methods in daily practice frequently. Functional tests such as observing the responses of the organs to certain stimuli and invasive structural tests, such as skin biopsy, microneurography SNS activity, and sural nerve biopsy, are currently practiced methods (21). On the other hand, the variability of $\mathrm{HR}$ and arterial blood pressure analyses are cost-effective methods and are frequently used to test the adrenergic activity in routine practice $(22,23)$. The HR reflects the balance between sympathetic and parasympathetic activities. Elevated HR was shown to be the risk factor for CAD, sudden cardiac death, and stroke developments. Moreover, it was demonstrated to predict all-cause mortality in the general population $(8,22)$. Although HR indicates sympathetic activity, it was affected by various conditions such as age, gender, BMI, smoking, physiological and oxidative stress, metabolic factors, and inflammation. Therefore, easily obtainable, cost-effective, and solid indices reflecting the sympathetic activity would contribute to interpreting the adrenergic functions better than HR. Typically, PR interval shortens with increased HR. Besides, the amount of decrease in PR interval with exercise was shown to be beyond the increase in HR $(23,24)$. Therefore, we may speculate that the PR interval has more predictive value than HR reflecting the autonomic balance. Hence, even though HR was higher in the MACE (+) group, it did not reach significance predicting MACE in this study.

The SN, AV node, and ventricular myocardium are under the grip of the autonomic nervous innervation. However, sympathetic and parasympathetic nerve distribution and tissue sensitivity to ANS differ in each part of the heart. Thus, the autonomic stimulus is distinct in the SN, AV node, and myocardium. The AV node has parasympathetic innervation dominantly and, by this way, regulates the HR by reducing stimuli arising from the SN $(14,24)$. Thus, autonomic nerve distribution and $\mathrm{AV}$ conduction properties may be altered, followed by AMI due to loss of neural innervation, secondary to the ischemia. Chen et al. (25) reported that autonomic neural denervation and subsequent sympathetic heterogeneous hyperinnervation triggered the malignant arrhythmias and sudden cardiac death in the post-Ml phase. That being the case, it can be asserted that autonomic nerve distribution and activity could be better interpreted by examining the PR interval in those with a steady AV conduction system (26).

PR interval is defined as AV block if it is over $200 \mathrm{~ms}$. In a recent study, patients were grouped according to the presence of the first-degree AV block. It was revealed that those with the AV block were more likely to have $A F, H F, C A D$, and mortality (27). In addition, in some previous trials, both PR interval prolongation and shortening are associated with adverse events in patients with CAD. However, the Atherosclerosis Risk in Communities study showed that while PR interval prolongation was not related to the development of $A F, P R$ interval shortening could predict the occurrence of the AF (28). Moreover, several studies demonstrated that PR shortening had more predictive usefulness than PR prolongation on the development of AF. Conversely, the PR interval prolongation reflects a more fibrotic and/or inflammatory environment in the $\mathrm{AV}$ conduction pathway.
On the other hand, the PR interval shortening was an indicator of increased sympathetic burden or parasympathetic withdrawal on the heart (29). In the current study, patients with AV conduction abnormalities were excluded. Hence, it was aimed to evaluate the pure effect of the sympathetic and parasympathetic effect on MACE by measuring the PR interval. Furthermore, given the value of PR interval is crucial in ANS activity estimation, this costeffective parameter may be added to other prognostic clinical factors to prognosticate future adverse events in MACE prediction better in all CAD patient groups. Various electrophysiological abnormalities were reported to be foreshadowing of the adverse cardiovascular events in patients with ACS. Therefore, ordinary parameters hidden in apparently normal ECG could be studied to predict MACE without expecting pathological effects of $\mathrm{Ml}$ on ECG (30).

In addition, $\mathrm{p}$ wave duration indicates atrial depolarization time and is the first component of the PR interval. The effect of $P$ wave prolongation on MACE was reported in previous studies (31). Although the $p$ wave duration was higher in the MACE (+) group, our study did not reach statistical significance. The PR interval shortening predicted MACE despite the prolonged $p$ wave duration. Thus, it can be emphasized that the PR interval has a substantial value in predicting MACE in patients with ACS. This is a single-center study with a limited number of patients. Therefore, a more extended follow-up period is required better to interpret the role of PR interval on MACE.

\section{CONCLUSION}

The PR interval at admission, probably indicating sympathetic dominancy, was an independent predictor of MACE during three years of follow-up in patients with ACS who were performed PCl. Thus, the PR interval may also be used as a non-invasive test to evaluate autonomic function in various patient groups.

Ethics Committee Approval: Approval was obtained from the Rize Governorship Provincial Health Directorate Ethics Committee (decision no: E-64247179-799, date: 26.05.2021).

Informed Consent: Informed consent was obtained from patients were included in the study.

Peer-review: Externally and internally peer-reviewed.

Author Contributions: Surgical and Medical Practices - A.S.Y., M.Ç.; Concept - A.S.Y., M.Ç.; Design - A.S.Y., G.Ç., M.Ç., Ö.F.Ç.; Data Collection and/or Processing - A.S.Y., M.Ç.; Analysis and/or Interpretation - A.S.Y., F.K., M.Ç., Ö.F.Ç.; Literature Search - A.S.Y., F.K., M.Ç.; Writing - A.S.Y., F.K., M.Ç.

Conflict of Interest: The authors have no conflict of interest to declare.

Financial Disclosure: The authors declared that this study has received no financial support.

Etik Komite Onayı: Rize Valiliği il Sağlık Müdürlüğü Etik Kurulu'ndan onay alındı (karar no: E-64247179-799, tarih: 26.05.2021).

Hasta Onamı: Hastalardan bilgilendirilmiş onam alındı, çalışmaya dahil edildi.

Hakem Değerlendirmesi: Editörler kurulu ve editörler kurulu dışında olan kişiler tarafından değerlendirilmiştir.

Yazar Katkıları: Cerrahi ve Medikal Uygulama - A.S.Y., M.Ç.; Konsept A.S.Y., M.Ç.; Dizayn - A.S.Y., G.Ç., M.Ç., Ö.F.Ç.; Veri Toplama veya İşleme - A.S.Y., M.Ç.; Analiz veya Yorumlama - A.S.Y., F.K., M.Ç., Ö.F.Ç.; Literatür Arama - A.S.Y., F.K., M.Ç.; Yazan - A.S.Y., F.K., M.Ç. 
Çıkar Çatışması: Yazarlar tarafından çıkar çatışması bildirilmemiştir.

Finansal Destek: Yazarlar tarafından finansal destek almadıkları bildirilmiştir.

\section{REFERENCES}

1. Aguado-Romeo MJ, Márquez-Calderón S, Buzón-Barrera ML. Hospital mortality in acute coronary syndrome: differences related to gender and use of percutaneous coronary procedures. BMC Health Serv Res 2007; 7: 110 .

2. Granger $C B$, Goldberg RJ, Dabbous O, Pieper KS, Eagle KA, Cannon $\mathrm{CP}$, et al. Predictors of hospital mortality in the global registry of acute coronary events. Arch Intern Med 2003; 163: 2345-53.

3. Lehmacher J, Neumann JT, Sörensen NA, Goßling A, Haller PM, Hartikainen TS, et al. Predictive value of serial ecgs in patients with suspected myocardial infarction. J Clin Med 2020; 9: 2303.

4. Wang X, Zhang L, Gao C, Zhu J, Yang X. Tpeak-Tend/OT interval predicts ST-segment resolution and major adverse cardiac events in acute ST-segment elevation myocardial infarction patients undergoing percutaneous coronary intervention. Medicine (Baltimore) 2018; 97: e12943. doi: 10.1097/MD.0000000000012943.

5. Timóteo AT, Mendonça T, Aguiar Rosa S, Gonçalves A, Carvalho R, Ferreira ML, et al. Prognostic impact of bundle branch block after acute coronary syndrome. Does it matter if it is left of right? Int J Cardiol Heart Vasc 2019; 22: 31-4

6. Lévy S. Bundle branch blocks and/or hemiblocks complicating acute myocardial ischemia or infarction. J Interv Card Electrophysiol 2018; 52: 287-92.

7. Wang SL, Wang CL, Wang PL, Xu H, Du JP, Zhang DW, et al. Resting heart rate associates with one-year risk of major adverse cardiovascular events in patients with acute coronary syndrome after percutaneous coronary intervention. Exp Biol Med 2016; 241: 478-84.

8. Palatini P. Heart rate and the cardiometabolic risk. Curr Hypertens Rep 2013; 15: 253-9.

9. Kennedy A, Finlay DD, Guldenring D, Bond R, Moran K, McLaughlin $J$. The cardiac conduction system: generation and conduction of the cardiac Impulse. Crit Care Nurs Clin North Am 2016; 28: 269-79.

10. Atterhög JH, Loogna E. P-R interval in relation to heart rate during exercise and the influence of posture and autonomic tone. J Electrocardiol 1977; 10: $331-6$

11. Levine GN, Bates ER, Bittl JA, Brindis RG, Fihn SD, Fleisher LA, et al. 2016 ACC/AHA guideline focused update on duration of dual antiplatelet therapy in patients with coronary artery disease: a report of the American College of Cardiology/American Heart Association Task Force on clinical practice guidelines. J Am Coll Cardiol 2016; 68: 1082-115.

12. Neumann FJ, Sousa-Uva M, Ahlsson A, Alfonso F, Banning AP, Benedetto U, et al. 2018 ESC/EACTS Guidelines on myocardial revascularization. Eur Heart J 2019; 40: 87-165.

13. Levy MN. Cardiac sympathetic-parasympathetic interactions. Fed Proc 1984; 43: 2598-602.

14. Kowallik P, Meesmann M. Independent autonomic modulation of the human sinus and $A V$ nodes: evidence from beat-to-beat measurements of PR and PP intervals during sleep. J Cardiovasc Electrophysiol 1995; 6: 993-1003
15. Moreira HG, Lage RL, Martinez DG, Ferreira-Santos L, Rondon MUPB, Negrão CE, et al. Sympathetic nervous activity in patients with acute coronary syndrome: a comparative study of inflammatory biomarkers. Clin Sci (Lond) 2017; 131: 883-95.

16. Graham LN, Smith PA, Stoker JB, Mackintosh AF, Mary DA. Sympathetic neural hyperactivity and its normalization following unstable angina and acute myocardial infarction. Clin Sci (Lond). 2004 Jun;106(6):605-11.

17. Xiong L, Liu Y, Zhou M, Wang G, Quan D, Shuai W, et al. Targeted ablation of cardiac sympathetic neurons attenuates adverse postinfarction remodelling and left ventricular dysfunction. Exp Physiol 2018; 103: 12219.

18. Roshanzamir S, Showkathali R. Takotsubo cardiomyopathy a short review. Curr Cardiol Rev 2013; 9: 191-6.

19. Gopinathannair R, Martins JB. Predicting sudden cardiac death in healthy humans: Is there more to autonomic balance than we know? Heart Rhythm 2008; 5: 306-7.

20. Martínez-Milla J, Raposeiras-Roubín S, Pascual-Figal DA, Ibáñez B. Role of Beta-blockers in cardiovascular disease in 2019. Rev Esp Cardiol (Engl Ed) 2019; 72: 844-52. (English, Spanish)

21. Grassi G, Esler M. How to assess sympathetic activity in humans. J Hypertens 1999; 17: 719-34.

22. Kishi T. Heart rate is the clinical indicator of sympathetic activation and prognostic value of cardiovascular risks in patients with hypertension. Hypertension 2020; 76: 323-4.

23. Skroza N, Mambrin A, Proietti I, Balduzzi V, Bernardini N, Marchesiello A, et al. Evaluation of cardiovascular risk in hidradenitis suppurativa patients using heart rate variability (HRV) analysis. Cardiovasc Ther 2020; 2020: 1321782. doi: $10.1155 / 2020 / 1321782$.

24. Martin P. The influence of the parasympathetic nervous system on atrioventricular conduction. Circ Res 1977; 41: 593-9.

25. Chen LS, Zhou S, Fishbein MC, Chen PS. New perspectives on the role of autonomic nervous system in the genesis of arrhythmias. J Cardiovasc Electrophysiol 2007; 18: 123-7.

26. Carruthers S, McCall B, Cordell B, Wu R. Relationships between heart rate and PR interval during physiological and pharmacological interventions. Br J Clin Pharmacol 1987; 23: 259-65.

27. Kwok CS, Rashid M, Beynon R, Barker D, Patwala A, Morley-Davies $A$, et al. Prolonged PR interval, first-degree heart block and adverse cardiovascular outcomes: A systematic review and meta-analysis. Heart 2016; 102: 672-80

28. Chamberlain AM, Agarwal SK, Folsom AR, Soliman EZ, Chambless $L E$, Crow $R$, et al. A clinical risk score for atrial fibrillation in a biracial prospective cohort (from the Atherosclerosis Risk in Communities [ARIC] Study). Am J Cardiol 2011; 107: 85-91.

29. Soliman EZ, Cammarata M, Li Y. Explaining the inconsistent associations of PR interval with mortality: the role of P-duration contribution to the length of PR interval. Heart Rhythm 2014; 11: 93-8.

30. Hayıroğlu Mi, Lakhani I, Tse G, Çınar T, Çinier G, Tekkeşin Ai. In-hospital prognostic value of electrocardiographic parameters other than stsegment changes in acute myocardial infarction: literature review and future perspectives. Heart Lung Circ 2020; 29: 1603-12.

31. Nakamoto T, Matsukawa K. Variability of ventricular excitation interval does not reflect fluctuation in atrial excitation interval during exercise in humans: AV nodal function as stabilizer. J Physiol Sci 2006; 56: 67-77. 